\title{
THE EXAMINATION OF THE TEXTURE OF UNFIRED REFRACTORIES.
}

At this point the President asked Dr. R. Lessing to show a series of specimens illustrating a method of testing he had devised five or six years ago for ascertaining the texture and rational composition of refractory mixtures before firing.

Dr. R. Lessing : The examination of the texture of finished refractories does not lend itself to quantitative treatment. Whilst a good deal of information on the rational composition and the mode of bondage can be gained by cutting and grinding sections of the fired goods, the quantitative ratio of such main constituents as "grog" and binding clay can only be estimated very roughly. In cases where the "grog" originally consisted of the same material as the binder, the difficulty of discriminating between the two in the fired state is still further accentuated and may make even such approximation impossible.

The importance of the relation of "grog," i.e. the previously fired constituent which forms the skeleton and the "green" clay which provides the binding matrix for the "grog," warranted the elaboration of a method for the quantitative separation of the goods before they undergo the final firing, or of the mixtures employed for moulding the articles.

The method devised consists of a simple process of elutriation by which the true clay substance of the "green" clay is removed by a gentle current of water and separated from the water by allowing it to settle out on standing. The rate of flow of water is so adjusted that the "grog" and also the heavy and coarse-grained residue of the "green" clay, consisting of sand, shale, or carbonaceous substances, are left behind in the elutriating vessel.

Elutriation is continued until the last clouds of clay substance are removed and the water becomes perfectly clear with the lightest portions of the residue floating just below the outlet.

A very simple form of elutriator accurate enough for works purposes consists of a tall glass cylinder, into which the water is passed through a glass tube reaching nearly to the bottom. The cylinder is placed in a bucket into which the clay suspension overflows, and from which the clear water is syphoned off after settling. For the purpose of the test, about 500 grams of the sample (which may be taken before or after "tempering," or from a moulded body before or after drying) are well soaked in water and washed into the cylinder. The resultant products of clay and residue are dried, and a screening test is then performed on the residue, from which the texture of the body and the ratio of "grog," granular (uncrushed) clay, shale, and coal can be ascertained.

The fractions from the screening test and the dried clay slip are weighed, and their percentage of the total is ascertained. A small portion of the sample is submitted to a moisture test, and all the figures obtained are reduced to the "dry" basis. 


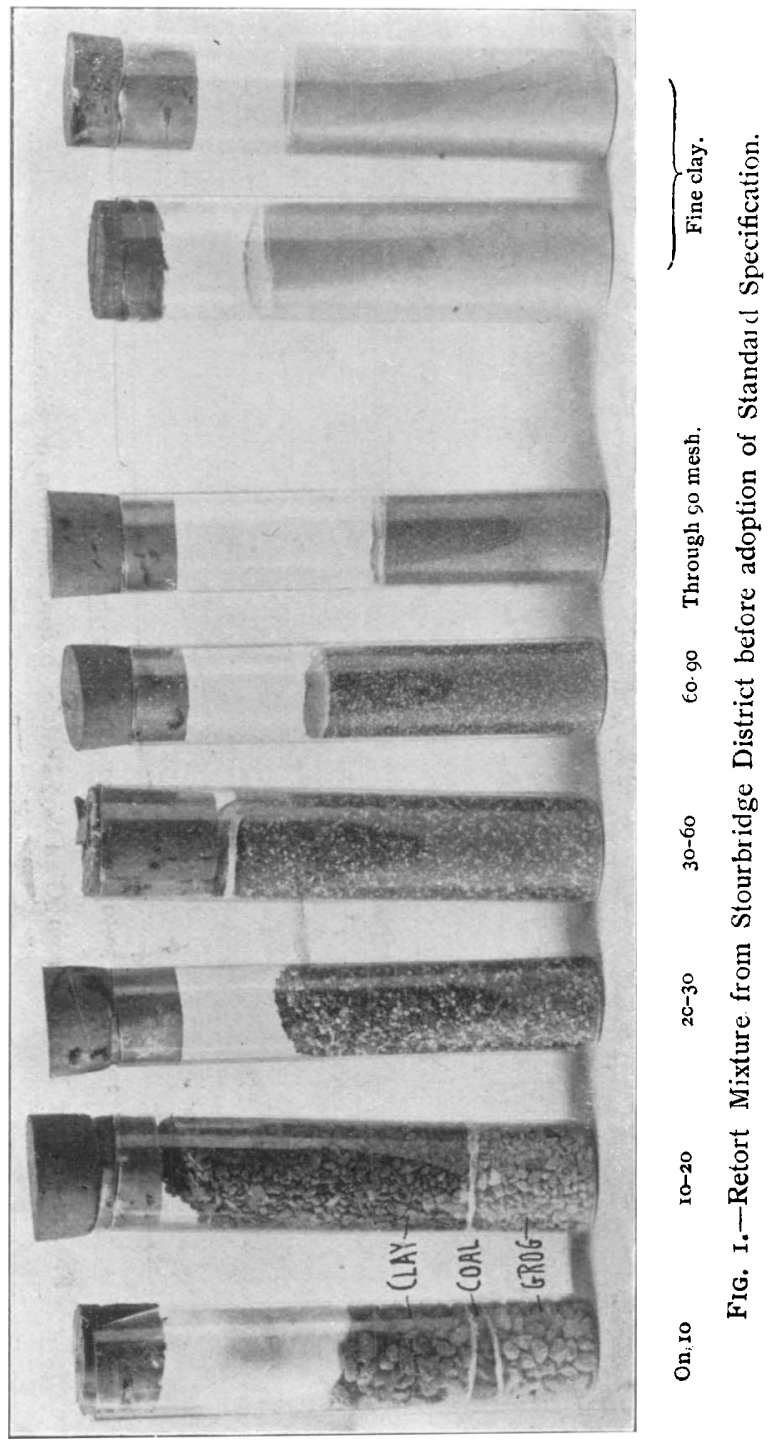



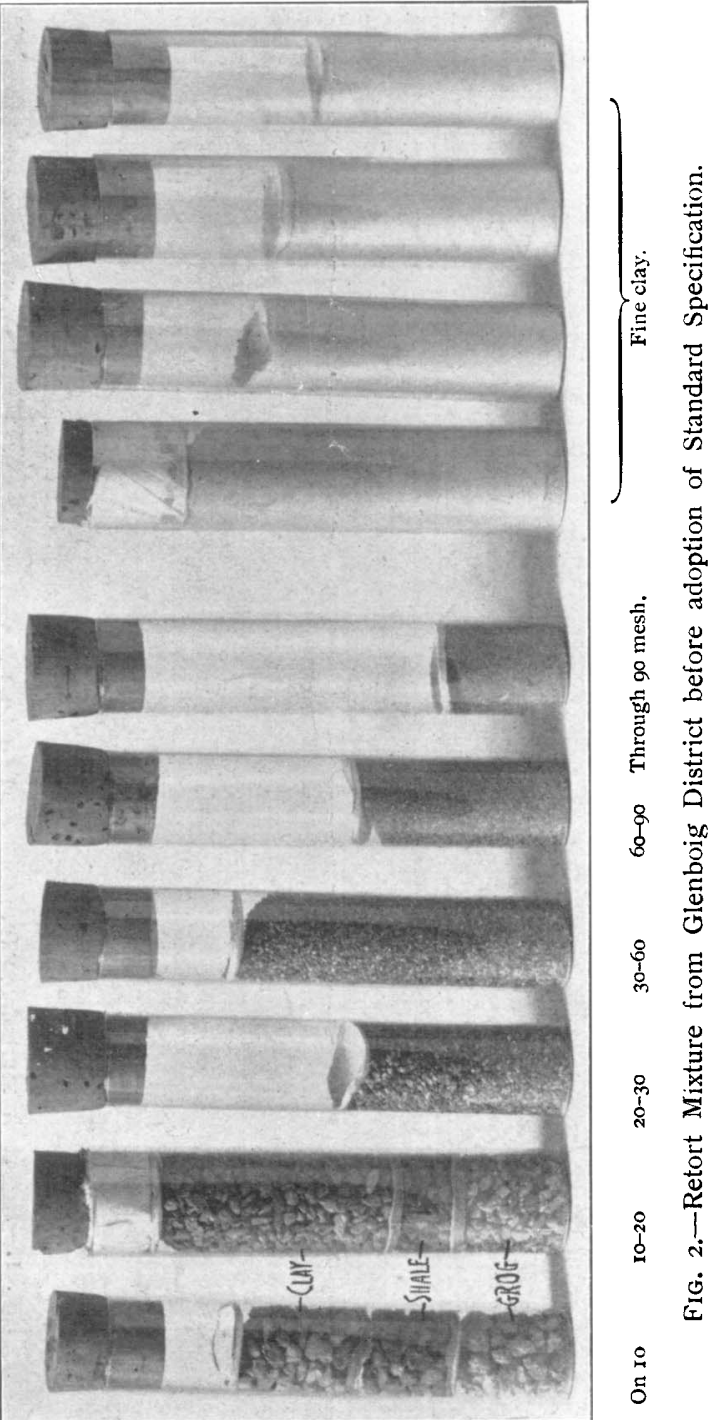


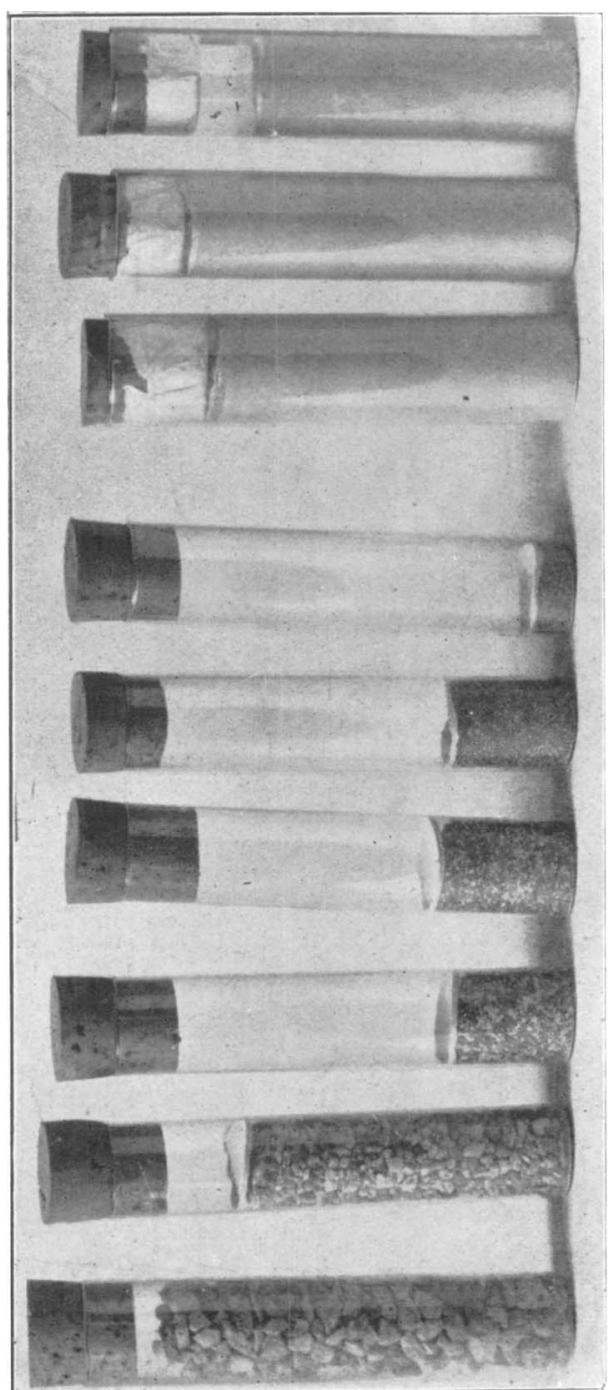

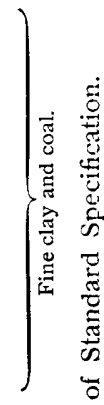

离

\&

战

总

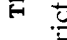

\&

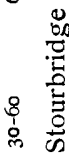

E

욤

放

范

空

옿 


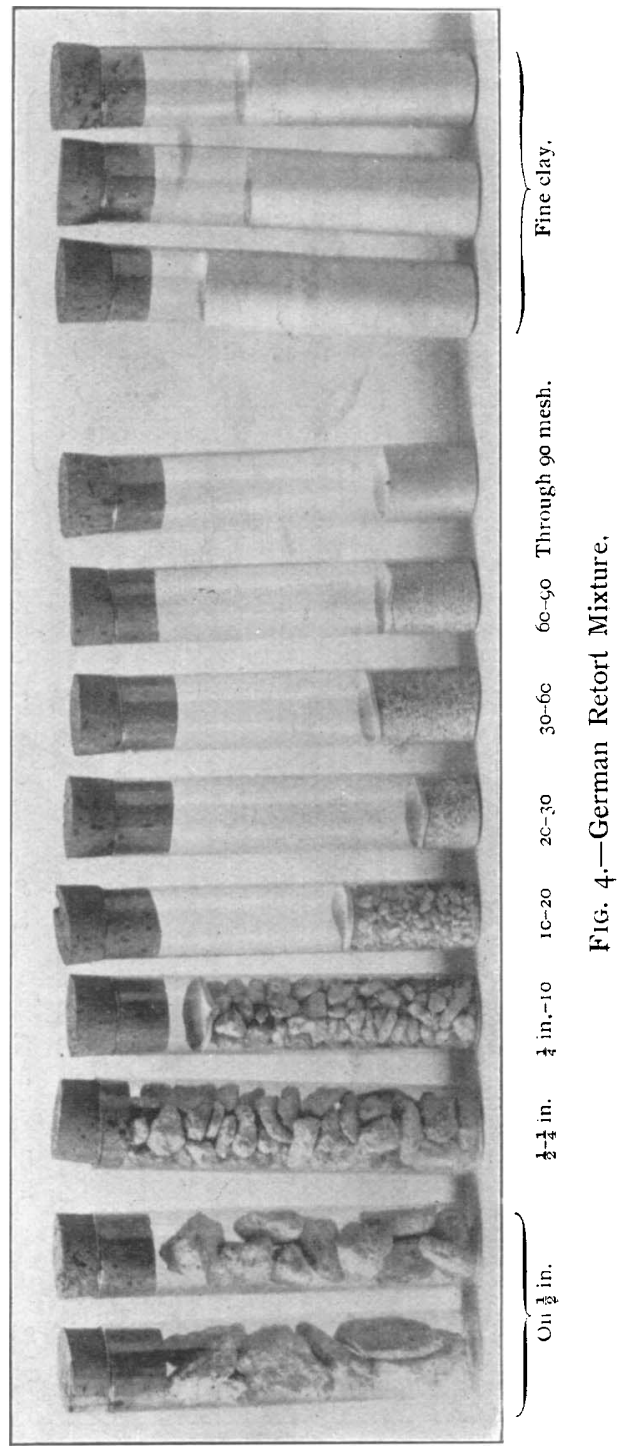


The fractions not passing through a twenty-mesh sieve contain particles which can be separated by hand-picking into such constituents as "grog," uncrushed "green" clay, shale, or coal. The "grog" itself may be further separated into broken brick, saggar, virgin clay, or other natural rock. Each sub-fraction is weighed and its percentage of the main fraction and of the total is ascertained. Where required, each constituent can be submitted to chemical analysis or physical tests.

The rational composition of the fractions can usually be ascertained with sufficient accuracy by estimating the proportion of light-coloured to darkcoloured particles by their appearance.

In cases where the type of raw materials used is known, such as in ordinary works control, a set of standard mixtures of varying proportions of "grog" and clay residue of each size can be prepared and forms a useful guide for comparison.

The results obtained from four typical samples are recorded below. In order to show the type of products obtained in the test, the photographs of the corresponding specimens are reproduced in Figs. I-4. The samples represent :-

I. Gas retort mixture from Stourbridge district before adoption of Gas Engineers' standard specification.

2. Gas retort mixture from Glenboig district before adoption of standard specification.

3. Gas retort mixture from Stourbridge district after adoption of standard specification.

4. Gas retort mixture from German firebrick works.

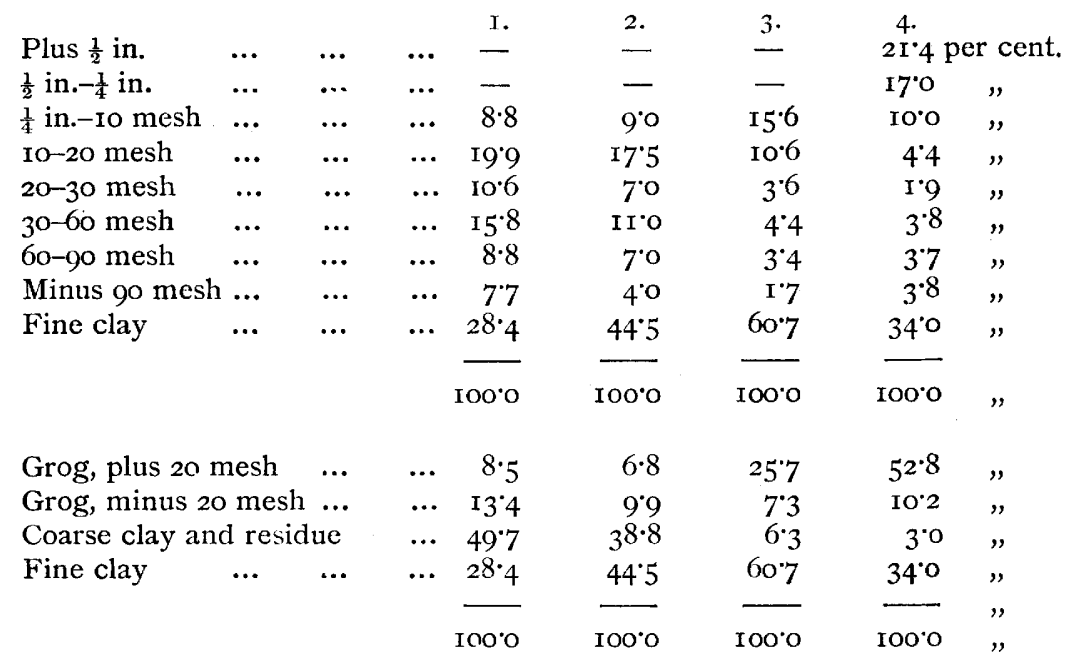

From a combined examination of the figures and the photographs of the actiual fractions obtained great differences will be observed in the composition of the various mixtures.

Samples I and 2 are typical of the manufacture of fireclay goods as carried on in this country before the adoption of the standard specification issued by the joint committee of the Institution of Gas Engineers and the Society of British Gas Industries. The outstanding feature in both samples from the two principal manufacturing districts is the small percentage of useful 


\section{I54 THE TEXTURE OF UNFIRED REFRACTORIES}

"grog." The preparation of the mixtures according to the old manufacturing method consisted in crushing and grinding the "green" clay together with "grog," which usually consisted of "wasters" in roller mills. In consequence a large proportion of the "grog" added was crushed to small size and dust, in which form it did not fulfil its proper function of supplying a rigid skeleton to the final product. On the other hand, a good deal of the "green" clay, being of a somewhat more elastic nature, escaped the grinding action, and was left in the form of granules of considerable size. These granules instead of acting as binder and embedding agent for the grog, formed themselves a skeleton which, however, was not rigid, but was subject to considerable shrinkage both in the drying stove and the fire kiln.

In order to comply with the requirements of the standard specification it is necessary to grind "grog" and "green" clay separately. This permits of the required grading of the "grog," the removal of fine dust from it, and the reduction of the "green" clay to fine powder. As will be seen from Fig. 3, the granular clay or shale and carbonaceous matter have disappeared entirely from the largest sizes of the mixture. The total percentage of "grog" has increased, and the proportion of fine to coarse "grog" has considerably decreased.

For comparison the results of a test carried out on a German gas retort mixture are recorded. They show that it is possible with a proper preliminary treatment of the ingredients to add a very much larger proportion of "grog" than has ever been attempted by the British makers, and at the same time considerably increase the size of the particles. The ratio of " grog" to " green" clay, which is about $I: 2$ in sample 3 , is practically reversed to $2: I$ in the German mixture.

Considering that the comparatively small increase from about 20 per cent. to 35 per cent. led in some cases at the start to the output of goods of doubtful mechanical strength, the conditions for the successful working up of a mixture, such as shown in No. 4 test, should be inquired into. It is evident from the results of the test that the binding clay had probably been submitted to washing in order to increase its plasticity-hence the small percentage of clay residuc. Further, it could be seen from the sample itself, and from the close adherence of the binding clay to the "grog" during elutriation, that the mixture had undergone a rather more thorough mechanical treatment and maturing process than was usual in English procedure up to quite recently.

From the examples quoted it will be seen that the tesi proposed, which has now been in use for about six years, can be profitably applied to the examination of unfired refractories of unknown composition. The principal use of the method is, however, for works purposes, and it affords a very simple means for the daily control of manufacturing operations from the mixing-pan to the kiln. 